tumorigenesis. This modification is dynamically modulated by proteins such as methyltransferases (writers), demethylases (erasers) and, recruitment of m6A-binding proteins (readers). In this study we investigated the different $\mathrm{m} 6 \mathrm{~A}$ methylation patterns between HeLa, SiHa and C33A cervical cancer (CC) cell lines and normal HCK1T cervical keratinocyte cells.

Methodology Gene expression levels of writers (METTL3, METTL14 and WTAP), erasers (ALKBH5 and FTO), and readers (IGF2BP-I, YTHDF1 and HNRNPA2B) was determined at mRNA and protein level by qPCR and Western blot, respectively. The quantification of RNA methylation was performed by colorimetric assay using the EpiQuick ${ }^{\circledR}$ methylation kit.

Result(s)* The expression of METTL3 and METTL14 methyltransferases in C33A cells was significantly higher $(\mathrm{p}=0,0274$ and $\mathrm{p}=0,0343$, respectively) while a statistically significant increase was observed for both $\mathrm{SiHa}$ and HeLa for WTAP compared to HCK1T cells ( $p=0,0153$ and $\mathrm{p}=0,0312$, respectively). In the case of demethylases, FTO was statistically increased in $\mathrm{C} 33 \mathrm{~A}$ and $\mathrm{SiHa}(\mathrm{p}=0,0015$ and $\mathrm{p}=0,0342$, respectively), while ALKBH5 was expressed at higher levels only in C33A $(\mathrm{p}=0,0054)$ in comparison with HCK1T cells. The expression of readers, YTHDF1 and IGF2BP-1, was statistically increased in C33A $(p=0,0058$ and $\mathrm{p}=0,0031$, respectively) and $\mathrm{SiHa}(\mathrm{p}=0,0123$ and $\mathrm{p}=0,0161$, respectively). Moreover, the methylation rate of all three CC cell lines was higher (HeLa 0.25\%, SiHa $0.17 \%$ and C33A $0.20 \%$ ) compared to HCK1T normal cervical cells $(0.14 \%)$.

Conclusion* Overall, the expression of writers, erasers and readers was enhanced in CC cells, highlighting a deregulation in this critical process. Ongoing experiments focus on the differential expression of the genes of the three groups in samples from cervical cancer with different degrees of dysplasia, to investigate their individual role in cervical cancer progression.

\section{PREDICTING THE RISK OF DISTANT RECURRENCE OF CERVICAL CANCER AFTER CONCURRENT CHEMORADIATION: A VALIDATION STUDY OF KGOG 1024}

'W Shin*, ${ }^{2} \mathrm{~J} \mathrm{Kim},{ }^{2} \mathrm{~S}$ Kang. ${ }^{1}$ Chungnam National University Hospital, obstetrics and gynecology, Korea, Rep. of South; ${ }^{2}$ National Cancer Center, Goyang-si, Korea, Rep. of South

\subsection{6/ijgc-2021-ESG0.97}

Introduction/Background* This study was aimed to validate the performance of the KGOG-1024 risk model predicting the risk of distant failure after chemoradiation in patients with locally advanced cervical cancer.

Methodology In the retrospective cohort of 297 patients who received concurrent chemoradiation for advanced cervical cancer, an individual risk was calculated using the KGOG 1024 risk model for each patients. The cohort was categorized into three risk groups (low, intermediate, and high-risk groups) according to a calculated risk. The mean of the calculated and the observed risk were compared within each group.

Result(s)* Low, intermediate, and high-risk groups were classified into 79, 143, and 68 patients. $(27.2 \%, 49.3 \%$, and

\begin{tabular}{ll} 
Abstract 1148 Table $1 \quad \mathrm{~N}=297$ & \\
\hline Age, years(Mean, Range) & $54(24-83)$ \\
Stage(No. of Patients, $\%)$ & \\
1 & $65(22.2)$ \\
2 & $178(60.8)$ \\
3 & $18(6.1)$ \\
4 & $32(10.9)$ \\
Histology(No. of Patients,\%) & \\
SCC & $257(86.5)$ \\
Adenosquamous \& Adenocarcinoma & $40(13.5)$ \\
Tumor size(Median, Range) & $4.5(0.6-11)$ \\
Serum SCC level(Median, Range) & $6.0(0.1-288)$ \\
Pelvic node status by PET(No. of Patients,\%) & \\
Negative & $99(33.3)$ \\
Positive & $198(66.7)$ \\
Paraaortic node status by PET(No. of Patients,\%) & \\
Negative & $242(81.8)$ \\
Positive & $54(18.2)$ \\
\hline
\end{tabular}

Abstract 1148 Table 2 Competing regression analysis of distantrecurrence free survival in locally advanced cervical cancer according to the risk groups identified by the KGOG-1024 risk criteria.

\begin{tabular}{lllll}
\hline & $\mathrm{N}(\%)$ & $\begin{array}{l}\text { Subhazard } \\
\text { ratios }\end{array}$ & $\begin{array}{l}\text { 95\% confidence } \\
\text { interval }\end{array}$ & P-value \\
\hline Low risk group & $79(27.2)$ & Reference & & 0.059 \\
$\begin{array}{l}\text { Intermediate risk } \\
\text { group }\end{array}$ & 143 & 1.82 & $.98-3.40$ & 0.003 \\
High risk group & $(49.3)$ & & $1.41-5.59$ & 0 \\
\hline
\end{tabular}

Abstract 1148 Table 3 Calculated and observed 5-year probability of of distant recurrence according to risk groups identified by the KGOG-1024 risk criteria.

\begin{tabular}{llll}
\hline & $\mathrm{N}(\%)$ & Calculated probability & Observed probability \\
\hline Low risk group & $79(27.2)$ & $12.4(12.1-12.7)$ & $16.4(8.2-26.9)$ \\
Intermediate risk group & $143(49.3)$ & $23.2(22.8-23.5)$ & $25.9(18.8-33.6)$ \\
High risk group & $68(23.5)$ & $50.7(47.9-53.5)$ & $36.3(24.7-48.0)$ \\
Total & $290(100.0)$ & $26.7(24.9-28.4)$ & $25.6(20.4-31.0)$ \\
\hline
\end{tabular}

Abstract 1148 Table 4 Additional risk variables associated with distant recurrence-free survival within low-risk group identified by the KGOG-1024 criteria (univariate analysis).

\begin{tabular}{llcc}
\hline & $\begin{array}{l}\text { Subhazard } \\
\text { ratio }\end{array}$ & $\begin{array}{l}95 \% \text { Confidence } \\
\text { interval }\end{array}$ & P-value \\
\hline Age & 1.05 & $1.00-1.11$ & 0.04 \\
Stage & Reference & $1.71-16.18$ & - \\
I-II & 5.3 & & 0.004 \\
III-IV & 1.42 & $0.93-2.16$ & 0.11 \\
Tumor & & & \\
size & & & \\
\hline
\end{tabular}


23.5\%) Risk of recurrence prediction was quite similar between calculated and observed. $(26.7 \%$ calculated and $25.6 \%$ observed) In low risk group, FIGO stage $(p=0.004)$ and old age $(p=0.04)$ was related of the risk of recurrence using univariate analysis.

Conclusion* The KGOG-1024 risk assessment model accurately predicted a distant recurrence after chemoradiation in patients with locally advanced cervical cancer, especially in intermediate-risk group. The model may be helpful in identifying patients who may benefit from adjuvant systemic treatment after chemoradiation.

\section{ROBOTIC-ASSISTED LYMPHADENECTOMY IN PREGNANCY AS CERVICAL CANCER STAGING - A CASE REPORT}

B Bittnerová*, R Pilka, V Staňková, M Janošík, P Dzvinčuk, R Marek. University Hospital Olomouc, Department of Obstetrics and Gynaecology, Olomouc, Czech Republic

\subsection{6/ijgc-2021-ESG0.98}

Introduction/Background* Cervical cancer represents one of the most commonly diagnosed tumours in pregnancy. Roboticassisted surgery is considered the standard method for surgical staging of cervical cancer. There is a very limited data in the available literature on the use of this method to perform lymphadenectomy in patients with cervical cancer during pregnancy. In the case report we describe the procedure of robotic pelvic lymphadenectomy in a patient with cervical cancer T1b in pregnancy.

Methodology A 43 years old nulliparous woman pregnant for the third time was referred to our department with a confirmed cervical adenocarcinoma in the 15 th week of pregnancy. According to the preoperative imaging examination (pelvic MRI scan, expert sonography), she suffered from stage $\mathrm{T} 1 \mathrm{~b}$ cervical cancer. The patient preferred the continuation of the pregnancy. Informed about the associated risks, she signed an informed refusal rejecting proposed radical surgical treatment. Based on the recommendation of the multidisciplinary team of gynaecological oncology, a surgical staging procedure was indicated before possible neoadjuvant systemic therapy. The robotic-assisted laparoscopic lymphadenectomy was performed on 21.5.2020 as a surgical modality of a minimally invasive approach. The procedure was performed without any complications, blood loss was up to $20 \mathrm{ml}$. Histopathological examination excluded the cancer dissemination into the lymph nodes. Subsequently, systemic treatment (cisDDP + Paclitaxel) was administered for 9 cycles to ensure adequate foetal maturity. Planned caesarean sections combined with a radical surgical treatment - radical hysterectomy and bilateral adnexectomy - were performed in gestational age 30 weeks and 5 days.

Result(s)* According to definitive histology and after the neoadjuvant treatment the stage of the disease was classified as FIGO IA1 ypT1a1 ypN0 ypMX Mandard TRG3. A close follow-up is ongoing in the patient.

Conclusion* In pregnant patients with cervical cancer, robotassisted laparoscopic lymphadenectomy is a very gentle and effective method of staging.

\section{Diagnostics}

\section{ACCURACY OF TRANSVAGINAL/TRANSRECTAL ULTRASOUND IN PREOPERATIVE PELVIC LYMPH NODE ASSESSMENT IN CERVICAL CANCER PATIENTS}

${ }^{1} \mathrm{~F}$ Fruhauf*, ${ }^{1} \mathrm{~T}$ Ballaschova, ${ }^{2} \mathrm{M}$ Zikan, ${ }^{1} \mathrm{~L}$ Dostalek, ${ }^{3} \mathrm{P}$ Dundr, ${ }^{1} \mathrm{D}$ Cibula, ${ }^{1} \mathrm{D}$ Fischerova. 'General University Hospital, First Faculty of Medicine, Charles University, Department of Obstetrics and Gynaecology, Prague, Czech Republic; ${ }^{2}$ Bulovka University Hospital, First Faculty of Medicine, Charles University, Department of Obstetrics and Gynaecology, Prague, Czech Republic; ${ }^{3}$ General University Hospital, First Faculty of Medicine, Charles University, Institute of Pathology, Prague, Czech Republic

\subsection{6/ijgc-2021-ESG0.99}

Introduction/Background* The aim of the study was to evaluate diagnostic accuracy of ultrasound in preoperative assessment of pelvic lymph nodes (LNs) in cervical cancer patients. Methodology Patients were retrospectively included if they met following inclusion criteria: 1) histologically verified cervical cancer; 2) preoperative ultrasound examination performed by one of three experienced sonographers (transvaginal or transrectal and transabdominal approach); 3) surgical lymph node staging (sentinel lymph node biopsy, SLNB and/or systematic pelvic lymphadenectomy, PLND or pelvic lymph node debulking). The final pathological examination served as the

Abstract 133 Table 1 Characterisation of study population

\begin{tabular}{|c|c|}
\hline Characteristic & Value $(\mathrm{N}=394)^{\mathrm{a}}$ \\
\hline Age, median (range), years & $43(20-82)$ \\
\hline BMI, median (range) & $24.5(14.1-44.9)$ \\
\hline \multicolumn{2}{|l|}{ Histological type } \\
\hline Squamous cell carcinoma & $298(75.6)$ \\
\hline Adenocarcinoma & $79(20.0)$ \\
\hline Neuroendocrine carcinoma & $13(3.4)$ \\
\hline Other & $4(1.0)$ \\
\hline \multicolumn{2}{|l|}{ Stage (FIGO 2009) } \\
\hline $\mid A 1$ & $18(4.5)$ \\
\hline IA2 & $15(3.8)$ \\
\hline IB1 & $236(60.0)$ \\
\hline IB2 & $44(11.1)$ \\
\hline IIA1 & $5(1.2)$ \\
\hline IIA2 & $2(0.5)$ \\
\hline IIB & $47(12.0)$ \\
\hline IIIA & $1(0.3)$ \\
\hline IIIB & $3(0.8)$ \\
\hline IVA & $2(0.5)$ \\
\hline IVB & $21(5.3)$ \\
\hline \multicolumn{2}{|l|}{ Type of pelvic LN staging } \\
\hline SLNB only & $87(22.1)$ \\
\hline SLNB + PLND & $241(61.1)$ \\
\hline PLND only & $35(8.9)$ \\
\hline Debulking of pelvic LNs only & $31(7.9)$ \\
\hline \multicolumn{2}{|l|}{ Pelvic LN status } \\
\hline Normal & $308(78.2)$ \\
\hline Macrometastases $( \pm \mathrm{MIC} \pm \mathrm{ITC})$ & $53(13.5)$ \\
\hline Micrometastases ( \pm ITC) & $23(5.8)$ \\
\hline Isolated tumour cells only & $10(2.5)$ \\
\hline
\end{tabular}

${ }^{a}$ Data are presented as number (percentage) of patients unless otherwise indicated. 